\title{
Open lung biopsy in children with diffuse lung disease
}

\author{
C. J. HEWITT, ^ D. HULL, and JEAN W. KEELING \\ From The Hospital for Sick Children, Great Ormond Street, London
}

\begin{abstract}
Hewitt, C. J., Hull, D., and Keeling, J. W. (1974). Archives of Disease in Childhood, 49, 27. Open lung biopsy in children with diffuse lung disease. Open lung biopsy is occasionally the only way to diagnose certain diffuse lung disorders in childhood. The clinical histories of 24 children with diffuse lung disease and the histological appearance of material obtained at open lung biopsy are reported, and published reports are reviewed.
\end{abstract}

Open lung biopsy is rarely performed in children. From the few published reports it was generally thought to help in establishing, confirming, or excluding a diagnosis in children with obscure diffuse lung disease (Weng et al., 1968; Stringer et al., 1968; Toyama et al., 1971). During 13 years, from 1959 to 1972,24 children with diffuse lung disease have undergone open lung biopsy at this hospital. This paper reports the clinical and histological features in these cases and discusses the indications and value of open biopsy.

\section{Materials and methods}

All children in the series had severe progressive lung disease. Radiologically the pathological process appeared diffuse, and its nature could not be determined by any other means. Included in the differential diagnosis of each case was at least one treatable condition.

Lung biopsy was obtained from the lingula in 20 cases, but in $\mathbf{4}$ the lingula appeared normal and the biopsy was taken from an area which appeared to be most severely affected radiologically.

The lung biopsy was taken unfixed to the histology department. In those cases where Pneumocystis carinii pneumonia was suspected, impressions were made from the cut surfaces of the lung on glass slides and stained by Geimsa's method, and in some cases the biopsy was divided and a small part frozen. The remainder of the biopsy was fixed in buffered formalin before paraffin embedding. Paraffin-embedded sections were stained with haematoxylin and eosin, Van Geison's method, Weigert's elastic tissue stain, Fordon and Sweet's method for reticulin, Geimsa and Grocott's modification of Gomori's methenamine silver stain, and Perls's stain for iron. Frozen sections were stained with haematoxylin and eosin and Jones's method.

Received 3 July 1973.

^Present address: Addenbrooke's Hospital, Cambridge.

\section{Results}

The clinical details and histological results of all the biopsies are in Table I.

In 5 cases, the paraffin-embedded sections of the biopsy showed typical changes of $P$. carinii pneumonia. In one of these cases the changes were present in haematoxylin and eosin stained cryostat sections, enabling diagnosis to be made on the same day as biopsy. In no case did we find that a positive diagnosis could be made from smears or impression preparations. Three biopsies from children with combined immune deficiency showed patchy thickening of alveolar walls with polymophonuclear leucocyte infiltration and no evidence of $P$. carinii infection.

Biopsies from 2 infants contained considerable amounts of haemosiderin in macrophages and septa in addition to fibrosis. 8 biopsies showed the changes of diffuse fibrosing alveolitis as the term is used by Scadding and Hinson (1967). Changes ranged from histiocytic infiltration of the alveolar walls with widespread desquamation of macrophages into the alveoli, with bizarre giant cell forms and peripherally sited lymphoid follicles, to gross fibrosis of alveolar walls with obliteration of many alveoli. Some biopsies showed a mixture of the above findings. The changes of Case 8 are described more fully. The biopsy from one girl contained multiple granulomata consisting of polymorphonuclear leucocytes and histiocytes with normal lung between them. This child was later shown to have chronic granulomatous disease.

The complications of the procedures were few. 3 patients had small pleural effusions after thoracotomy, which resolved spontaneously, and 3 had subcutaneous surgical emphysema. In only 
Clinical details and findingsin

\begin{tabular}{|c|c|c|}
\hline Case no. & Age at onset of illness & Presenting features \\
\hline 1 & Birth & $\begin{array}{l}\text { Anorexia, upper respiratory symptoms; } \\
\text { chest infection at } 19 \mathrm{mth}\end{array}$ \\
\hline 2 & Birth & $\begin{array}{l}\text { Weak suck, poor weight gain; recurrent } \\
\text { coryza, cough, intermittent fevers from } \\
\text { age } 8 \mathrm{mth}\end{array}$ \\
\hline 3 & $6 \frac{1}{2} \mathrm{yr}$ & Cough, tachypnoea, fever \\
\hline 4 & $1 \frac{1}{2} \mathrm{yr}$ & $\begin{array}{l}\text { Episodes of cough, dyspnoea, cyanosis, } \\
\text { fever, bronchospasm }\end{array}$ \\
\hline 5 & $41 \mathrm{yr}$ & $\begin{array}{l}\text { Episodes of cough, wheezing, anorexia, } \\
\text { lethargy }\end{array}$ \\
\hline 6 & Birth & $\begin{array}{l}\text { Poor weight gain, intermittent cough; } \\
\text { dyspnoea at age } 31 \text { yr }\end{array}$ \\
\hline 7 & $8 \mathrm{dy}$ & $\begin{array}{l}\text { Tachypnoea, slow feeder; cyanosed at age } \\
5 \mathrm{mth}\end{array}$ \\
\hline 8 & Birth & $\begin{array}{l}\text { Slow feeder; poor weight gain; cough, } \\
\text { wheeze, general malaise at } 2 \mathrm{mth}\end{array}$ \\
\hline 9 & Birth & $\begin{array}{l}\text { Slow feeder, coryza, and persistent cough } \\
\text { at } 2 \mathrm{mth}\end{array}$ \\
\hline 10 & Early infancy & $\begin{array}{l}\text { Tachypnoea and clubbing of fingers at } 9 \\
\text { mth of age }\end{array}$ \\
\hline 11 & Birth & $\begin{array}{l}\text { Persistent vomiting, failure to thrive, } \\
\text { cough }\end{array}$ \\
\hline 12 & $1 \frac{3}{4 r}$ & Anorexia, cough, fever dypsnoea \\
\hline 13 & $5 \mathrm{wk}$ & $\begin{array}{l}\text { Poor weight gain; vomiting, diarrhoea, } \\
\text { cough }\end{array}$ \\
\hline 14 & $6 \mathrm{mth}$ & Chest infection, cyanosis, cough \\
\hline 15 & $1 \mathrm{yr}$ & Cough, fever, dyspnoea, vomiting \\
\hline 16 & $1 \mathrm{mth}$ & Cough, slow feeder \\
\hline 17 & $3 \mathrm{wk}$ & $\begin{array}{l}\text { Septic spot on leg; at } 2 \text { mth tachypnoea } \\
\text { and rib retraction, diarrhoea }\end{array}$ \\
\hline 18 & $9 \mathrm{mth}$ & $\begin{array}{l}\text { Recurrent episodes of 'bronchitis', } \\
\text { anorexia, poor weight gain }\end{array}$ \\
\hline 19 & $1 \mathrm{mth}$ & $\begin{array}{l}\text { Weak cry, abnormal chest movements, } \\
\text { tachypnoea }\end{array}$ \\
\hline 20 & Birth & $\begin{array}{l}\text { Feeding difficulty and vomiting; at } 6 \\
\text { mth episode of dyspnoea and cyanosis }\end{array}$ \\
\hline 21 & $7 \mathrm{mth}$ & $\begin{array}{l}\text { Ulcerated nodular lesion on leg; later } \\
\text { episodes of cough, dyspnoea, heart } \\
\text { failure }\end{array}$ \\
\hline 22 & Birth & $\begin{array}{l}\text { Slow feeder; episodes of cyanosis when } \\
\text { crying; cardiac failure }\end{array}$ \\
\hline 23 & Birth & $\begin{array}{l}\text { Vomited cow's milk; recurrent episodes } \\
\text { of cough, fever, tachypnoea }\end{array}$ \\
\hline 24 & Birth & $\begin{array}{l}\text { Tachypnoea, failure to thrive, } \\
\text { hepatomegaly }\end{array}$ \\
\hline
\end{tabular}

Chest $x$-ray appearances

Diffuse linear and patchy shadowi mainly perihilar

Diffuse mottled shadowing

consolidation and linear shadowing; loss of cardiac outlire

Overinflated chest; diffuse linear shadowing; cardiomegaly and $\vec{\omega}$ prominent pulmonary artery

Diffuse linear and mottled shadown mainly perihilar

Diffuse mottled shadowing obscuring diaphragm and heart borders

Minimal changes; suggestion of decreas translucency all areas

Diffuse hazy shadowing of varying density and loss of cardiac outline

Diffuse opacity most marked in perthila region

Minimal mottled shadowing both $\overrightarrow{\text { lungs }}$

Diffuse hazy shadowing, mainly pe्सinhil some nodularity in perihilar region Diffuse consolidation sparing peripery

Diffuse hazy shadowing with somectinea patchy shadowing right middle 1 be and left upper lobe

Diffuse patchy opacities

Diffuse hazy shadowing with airbronchogram

Consolidation of right lower lobe, shadowing left base

Patchy changes both upper lobes lungs overinflated; changes of rapid onset

Diffuse nodular patchy shadowing particularly perihilar

Diffuse hazy shadowing, high diaphrag

Diffuse changes with linear shadow patchy opacities, mainly perihilar consolidation at right base

Extensive patchy shadowing bilate हुํำ

Extensive patchy shadowing

Diffuse mottling and linear shado

Diffuse bilateral mottling, mainly perihilar; normal heart size

one was there a serious complication: this was a large pneumothorax that required reinsertion of a pleural drain, after which it resolved. Only one child died within 24 hours of the lung biopsy, and his death was not related to any complication of the open lung biopsy procedure. $\mathrm{He}$ was already in extremis before biopsy. 3 other children died within one week of the lung biopsy, but again death was attributable to the underlying lung problem rather than to a complication of the biopsy itself.

At the time of writing, 13 of the 24 patients have died. Of those with cryptogenic fibrosing alveolitis, 
ldren who had open lung biopsy

\begin{tabular}{|c|c|c|c|}
\hline Age at biopsy & Histological diagnosis & Final clinical diagnosis & Outcome \\
\hline $4 \mathrm{yr}$ & Cryptogenic fibrosing alveolitis & $\begin{array}{l}\text { Fibrosing alveolitis and features of } \\
\text { autoimmune disease }\end{array}$ & Died age $6 \frac{1}{2}$ yr \\
\hline $18 \mathrm{mth}$ & Cryptogenic fibrosing alveolitis & Fibrosing alveolitis & Alive, improving; aged $11 \frac{1}{2}$ yr \\
\hline 6 yr $8 \mathrm{mth}$ & Cryptogenic fibrosing alveolitis & Fibrosing alveolitis & Well; aged 9 yr \\
\hline 5 yr $5 \mathrm{mth}$ & Cryptogenic fibrosing alveolitis & Fibrosing alveolitis & Died aged 5 yr 7 mth \\
\hline $5+y r$ & Cryptogenic fibrosing alveolitis & $\begin{array}{l}\text { Fibrosing alveolitis; evidence of } \\
\text { autoimmune disease }\end{array}$ & Well; aged $12 \frac{1}{2}$ yr \\
\hline 4 yr $1 \mathrm{mth}$ & Cryptogenic fibrosing alveolitis & Fibrosing alveolitis & Died aged $4 \frac{1}{2}$ yr \\
\hline 8 mth & Cryptogenic fibrosing alveolitis & Fibrosing alveolitis & Died aged $11 \mathrm{mth}$ \\
\hline $4 \mathrm{mth}$ & Cryptogenic fibrosing alveolitis & Fibrosing alveolitis & Alive, tachypnoeic; aged $3 \frac{1}{2}$ yr \\
\hline $5 \mathrm{mth}$ & No histological abnormality & Probable fibrosing alveolitis & Alive; fairly well; aged $9 \mathrm{mth}$ \\
\hline $6 \frac{1}{2} \mathrm{yr}$ & No histological abnormality & Probable fibrosing alveolitis & Alive, aged $6 \frac{8}{4} \mathrm{rr}$ \\
\hline $8 \mathrm{mth}$ & $P$. carinii pneumonia & $\begin{array}{l}\text { Combined immune deficiency state } \\
\text { and pneumocystis pneumonia }\end{array}$ & Died aged $9 \mathrm{mth}$ \\
\hline 2 yr & $P$. carinii pneumonia & $\begin{array}{l}\text { Hypo- } \gamma \text {-globulinaemia and } \\
\text { pneumocystis pneumonia }\end{array}$ & $\begin{array}{l}\text { Alive (not seen since aged } 4 \text { yr } \\
\text { in 1961) }\end{array}$ \\
\hline $6 \mathrm{mth}$ & $P$. carinii pneumonia & Combined immune deficiency state & Died aged $10 \mathrm{mth}$ \\
\hline $1 \mathfrak{t} \mathrm{yr}$ & $P$. carinii pneumonia & Hypo- $\gamma$-globulinaemia & $\begin{array}{l}\text { Alive (not seen since aged } 6 \mathrm{yr} \text { in } \\
\text { 1969) }\end{array}$ \\
\hline 1 yr $2 \mathrm{mth}$ & $P$. carinii pneumonia & $\begin{array}{l}\text { Resolving pneumocystis } \\
\text { pneumonia and bacterial } \\
\text { pneumonia }\end{array}$ & $\begin{array}{l}\text { Died aged } 1 \text { yr } 2 \text { mth, } 1 \text { week } \\
\text { after biopsy }\end{array}$ \\
\hline & Nonspecific inflammatory changes & $\begin{array}{l}\text { Combined immune deficiency state } \\
\text { and bacterial pneumonia }\end{array}$ & $\begin{array}{l}\text { Died at } 6 \mathrm{mth}, 1 \text { week afte } \\
\text { biopsy }\end{array}$ \\
\hline $3 \mathrm{mth}$ & Nonspecific inflammatory changes & $\begin{array}{l}\text { Combined immune deficiency } \\
\text { state; disaccharide intolerance }\end{array}$ & Died $24 \mathrm{hr}$ after biopsy \\
\hline $2 \frac{1}{2}$ yr & No histological abnormality & $\begin{array}{l}\text { Multisystem disease with evidence } \\
\text { of autoimmune state }\end{array}$ & Died aged 3 yr $1 \mathrm{mth}$ \\
\hline $3 \mathrm{mth}$ & No histological abnormality & $\begin{array}{l}\text { Bilateral diaphragmatic palsy of } \\
\text { unknown aetiology; pneumonia }\end{array}$ & Died 12 dy after biopsy \\
\hline 2 yr $8 \mathrm{mth}$ & Nonspecific inflammatory changes & $\begin{array}{l}\text { Methylmalonic acidaemia, } \\
\text { possibly viral pneumonia and } \\
\text { pulmonary haemorrhage, } \\
\text { cirrhosis, mental retardation } \\
\text { Chronic granulomatous disease }\end{array}$ & Alive, well, aged $8 \frac{1}{2}$ yr \\
\hline 5 mth & $\begin{array}{l}\text { Nonspecific inflammatory changes, } \\
\text { some haemorrhages }\end{array}$ & $\begin{array}{l}\text { Ventricular septal defect, } \\
\text { persistent ductus arteriosus; } \\
\text { large left to right shunt }\end{array}$ & Well, aged $4 t$ yr \\
\hline 2 yr $10 \mathrm{mth}$ & $\begin{array}{l}\text { Pulmonary haemosiderosis and } \\
\text { fibrosis }\end{array}$ & $\begin{array}{l}\text { Probable idiopathic pulmonary } \\
\text { haemosiderosis with iron } \\
\text { deficiency anaemia }\end{array}$ & Improving, aged $3 \frac{1}{2}$ yr \\
\hline $3 \mathrm{mth}$ & $\begin{array}{l}\text { Pulmonary haemosiderosis and } \\
\text { fibrosis }\end{array}$ & $\begin{array}{l}\text { Infradiaphragmatic total } \\
\text { anomalous pulmonary venous } \\
\text { drainage }\end{array}$ & Died 4 dy after biopsy \\
\hline
\end{tabular}

4 have died. In the pneumocystis pneumonia group 3 died, these being the 2 with combined immune deficiency state and one who was apparently immunologically normal. The 2 survivors both had hypo- $\gamma$-globulinaemia. Of the nondiagnostic and 'normal' biopsy group, 4 died.
The following case reports illustrate the main clinical groups.

\section{Case reports}

Combined immune deficiency state and $P$. carinii pneumonia. Case 13. A male born 2 weeks 


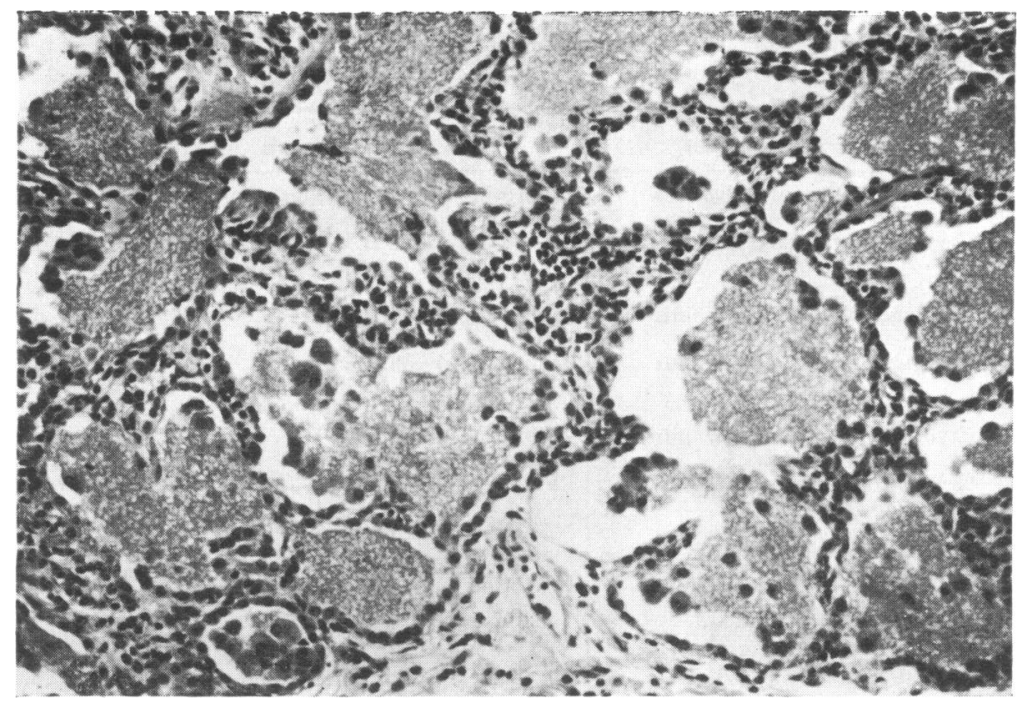

FIg. 1.-Case 13. P. carinii pneumonia. Alveoli are filled by foamy material; there is thickening and cellular infiltration of the alveolar walls. (Haematoxylin eosin. $\quad \times 133$.

postmature, after a normal pregnancy, by normal delivery and weighed $3.4 \mathrm{~kg}$. At 10 weeks of age he failed to gain weight, and began to vomit and to have diarrhoea. On admission to hospital he was found to have oral thrush, a nasal discharge, and conjunctivitis. Investigation suggested a combined immune deficiency state.

When he was transferred here at 5 months of age, both his length and weight were below the 3 rd centile. Small lymph nodes were palpable in his neck and inguinal regions but no tonsils could be seen. There were no respiratory symptoms or abnormal signs. On $x$-ray the lung fields were clear and no thymic shadow was seen.

The lymphocyte count varied from 74 to $336 / \mathrm{mm}^{3}$. Lymphocyte function tests showed a partial lymphocyte transformation response to phytohaemagglutinin, with excessive unstimulated activity. Though Candida was grown from a mouth swab, the Candida skin test was negative. Immunoglobulin levels were IgG $260 \mathrm{mg} / 100$ $\mathrm{ml}$, IgA $0 \%$, IgM $78 \%$ of reference normal serum. His blood group was $\mathrm{O}$ rhesus positive but the isohaemagglutinins at 5 months of age were anti-A $1: 1$, anti-B 0 . Faecal fat excretion was $50 \%$ of the oral intake and a glucose tolerance test gave a flat curve. Sweat electrolyte concentrations were normal.

Progress. Human $\gamma$-globulin was given from the 5 th month at a dose of $0.1 \mathrm{~g} / \mathrm{kg}$ body weight. At 6 months of age he developed tachypnoea with a cough and chest $x$-ray showed widespread hazy shadowing. A lung biopsy was arranged. In view of serious deterioration, he was started on pentamidine $4 \mathrm{mg} / \mathrm{kg}$ intramuscularly daily immediately, 48 hours before biopsy.

Histology report. There was diffuse thickening of the alveolar walls with cellular infiltration, mainly histiocytic, but lymphocytes and occasional plasma cells were $\vec{\vartheta}$ present. Many alveoli were filled with foamy eosinophilic material in which basophilic 'dots' were seen (Fig. 1), though in others this material was seen only in patches lining the alveolar walls. Geimsa staining showed clear cysts containing up to 8 strongly basophilic bodies lying within the foamy material. In sections stained by Grocott-Gomori's methenamine silver method the foamy material is black (Fig. 2).

Occasional macrophages were seen within alveoli. No polymorphonuclear leucocytic infiltration was present. No increase in reticulin, collagen, or elastic fibrils could be shown in the alveolar walls.

Having confirmed the diagnosis of pneumocystis pneumonia, the pentamidine was continued for one month. Clinically and radiologically his respiratory problem improved. However, severe diarrhoea with malnutrition became an increasing problem despite a diet free of disaccharides and added medium chain triglycerides. He became severely emaciated and died from a Staphylococcus aureus septicaemia at 10 months of age.

At necropsy the abnormal findings were a minute thymus, atrophic lymph nodes throughout the body, absent tonsils. Lungs weighed $62 \mathrm{~g}$ and $56 \mathrm{~g}$ and were bulky, pink, well aerated, oedematous; no pleural effusions, adhesions at thoracotomy site. Histological examination confirmed the absence of lymphoid follicles in lymph nodes, tonsillar area, spleen, and appendix. The thymus comprised only the supporting framework and vasculature.

The lungs contained aterectatic foci and there was compensatory emphysema. Some alveoli contained fragments of foamy eosinophilic material in which basophilic dots were seen: many more contained oedema 


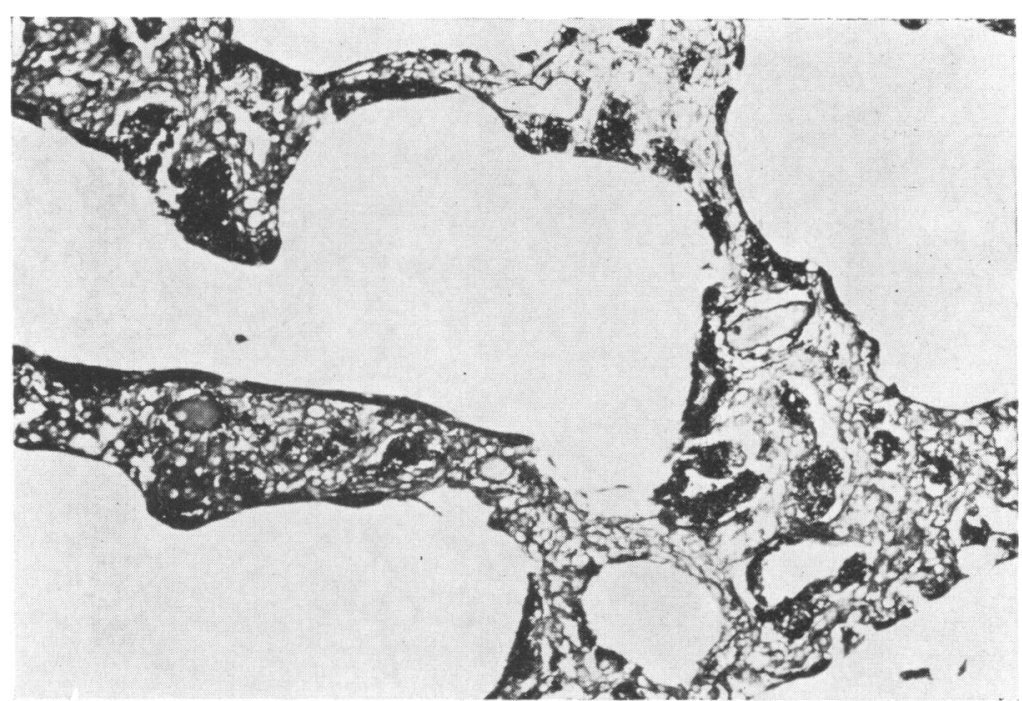

Fig. 2.-Case 13. P. carinii pneumonia. Some of the alveoli are dilated; the foamy material is closely applied to the alveolar walls. (Grocott-Gomori. $\quad \times 133$.

fluid. Occasional alveoli contained macrophages with foamy cytoplasm. Congested blood vessels were present in alveolar walls but there was no cellular infiltration. Alveolar epithelium was a flattened layer.

Combined immune deficiency syndrome and lung showing 'nonspecific' inflammatory changes. Case 16. A female born at 37 weeks' gestation weighing $3.5 \mathrm{~kg}$. Her brother died the previous year with combined immune deficiency. She was well until 4 weeks of age when she developed a cold, became 'snuffly', and sucked poorly. One week later she developed diarrhoea which led to her admission at 6 weeks of age in February 1969.

On examination she looked a healthy baby, with weight on the 25th centile. No superficial lymph nodes could be palpated. She had a distressing cough but clinically and on $x$-ray the lung fields were clear.

The lymphocyte count varied between 374 and 574 cells $/ \mathrm{mm}^{3}$. Lymphocyte transformation tests were initially normal, but later the response to phytohaemagglutinin was reduced. Skin tests to Candida and to dinitrofluorobenzene after previous exposure were negative. Serum immunoglobulins on admission were IgG $440 \mathrm{mg} / 100 \mathrm{ml}$, IgA $5 \%$ and $\operatorname{IgM~} 20 \%$ of the reference normal serum, but these later fell. No isohaemagglutinins were detected at 4 months of age. No thymic shadow was seen on $x$-ray.

Progress. Human $\gamma$-globulin was given: $0.05 \mathrm{~g} / \mathrm{kg}$ daily for 5 days followed by weekly injections of 0.025 $\mathrm{g} / \mathrm{kg}$ intramuscularly. At 2 months of age she had an infusion of her father's bone marrow, and this was felt to have a transient beneficial effect.

At 4 months of age she developed a persistent cough with fever. Rales were heard over the right lower lobe.
Chest $x$-ray showed consolidation in the right lower lobe, and patchy shadowing at the left base. Broad spectrum antibiotics were given without improvement. Over a 3-week period $x$-rays showed an extensive and progressing condition, and an open lung biopsy was performed from the right upper lobe. Histological examination showed that the bronchi and bronchioles contained mucopurulent exudate. The alveolar walls were thickened by histiocytic and polymorphonuclear leucocyte infiltration which was also present in the alveoli. No increase of collagen, reticulin, or elastic tissue was seen in the alveolar walls. No foamy material with staining characteristics of $P$. carinii was present. A small right apical pneumothorax was noted one week later. The presence of pneumocystis, cytomegalic inclusion disease, and fungal infection were excluded. Antibiotics and human $\gamma$-globulin were continued, but her course continued to be downhill and she died at 6 months of age. A blood culture taken on the last day of life grew Esch. coli. Necropsy revealed a diffuse bacterial pneumonia.

Cryptogenic fibrosing alveolitis confirmed histologically. Case 8. A male born at term by normal delivery, weighing $3 \cdot 2 \mathrm{~kg}$, and cried immediately. From birth he was slow to feed and gain weight. At 2 months of age he developed a cough accompanied by wheezing and general malaise. At 11 weeks of age he was admitted to hospital when he was noted to have moderate dyspnoea and central cyanosis. His chest was overinflated and coarse rales and expiratory rhonchi could be heard in all areas. No other abnormal physical signs were to be found.

Hb was $10.9 \mathrm{~g} / 100 \mathrm{ml}$, white blood count $9000 / \mathrm{mm}^{3}$ of which $39 \%$ were polymorphonuclear cells and $53 \%$ lymphocytes, with $6 \%$ monocytes and $2 \%$ eosinophils. 


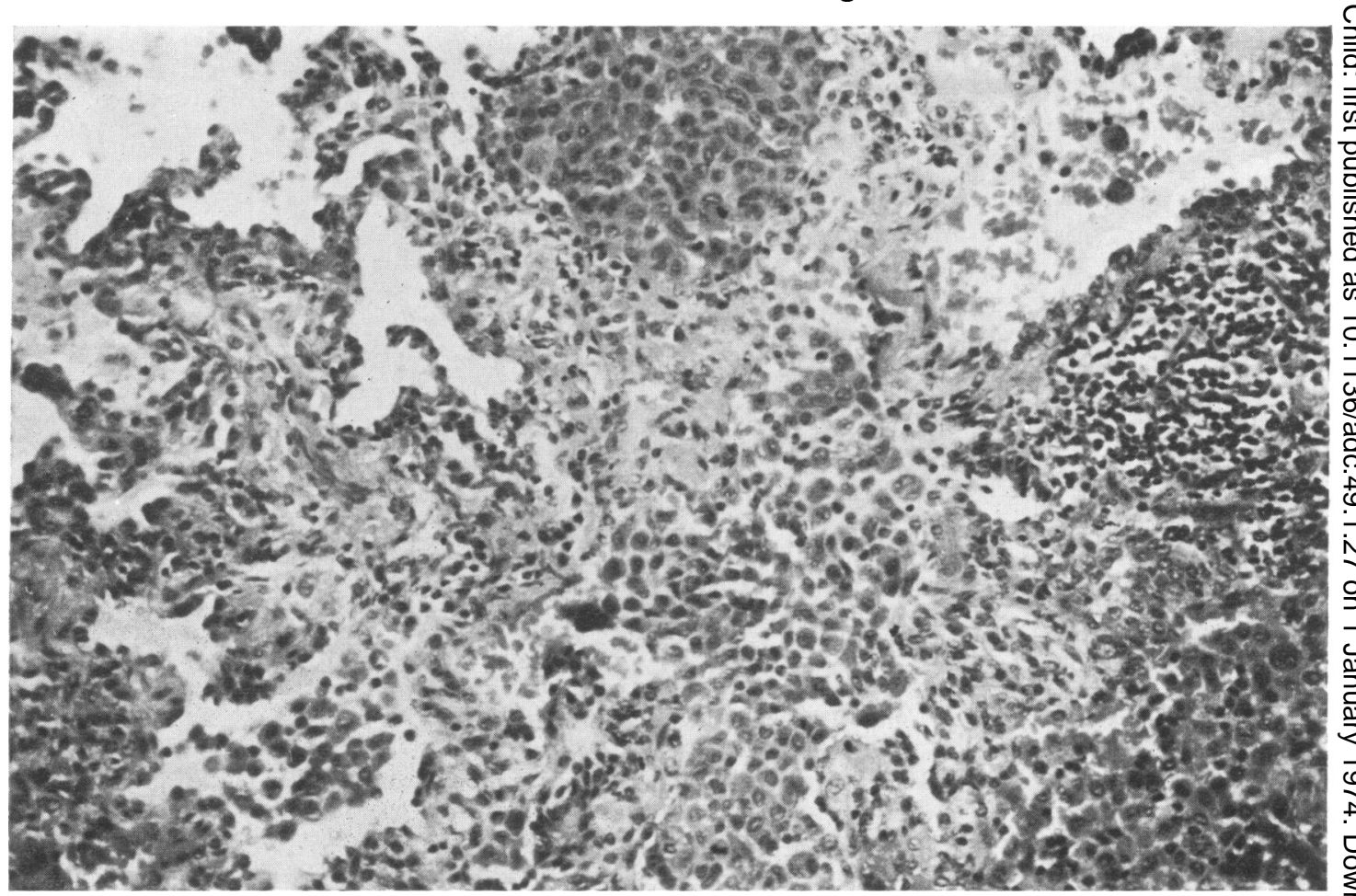

Fig. 3.-Case 8. Fibrosing alveolitis. Thickening of the alveolar walls and desquamation of alveolar lining cells which completely fill some alveoli, aggregation of lymphocytes on right. (Haematoxylin eosin. $\times 200$.)

Chest $x$-rays showed patchy shadowing in both lung fields, which became more extensive in the weeks after admission. ECG showed some right ventricular hypertrophy. Blood urea, electrolytes, and sweat electrolytes were normal. Duodenal juice enzyme concentrations were also normal. Urine examination showed an excess of lactose, glucose, and sucrose, and the stools contained excess galactose, glucose, and fructose. Bacteriological investigations included a rubella haemagglutination inhibition titre of $1: 8$ which, when repeated at 4 months of age, had fallen to $1: 4$. Toxoplasma dye test was negative. The cytomegalovirus complement fixation titre was 1:4 and remained unchanged, and tests for syphilis were negative. Mycoplasma was not isolated from the throat swab and cold agglutinins were not present. Ciné swallow showed normal deglutition and chest screening showed poor respiratory excursions with some air trapping. Serum immunoglobulins were IgG $720 \mathrm{mg} / 100 \mathrm{ml}$, IgA $16 \%$ and IgM $140 \%$ of reference normal serum. Plasma and urinary amino acid patterns were normal.

Therapy before biopsy included oxygen, antibiotics, digoxin, physiotherapy, and a disaccharide-free diet. His condition steadily deteriorated and an open lung biopsy was performed at the age of 4 months. Histology of the lingular sample showed diffuse thickening of the alveolar walls with histiocytic infiltration (Fig. 3).
Increased reticulin was laid down around the histiocytes $\overrightarrow{\vec{\overrightarrow{ }}}$ and collagen fibrils were present. Some alveoli $\frac{3}{3}$ contained macrophages. Bacterial cultures of lung tissues produced no growth. After biopsy he was started on prednisolone $10 \mathrm{mg}$ daily, and thereafter steady improvement was noted both clinically and radiologically. After $\mathbf{1 0}$ days the prednisolone dose was? reduced to $7.5 \mathrm{mg}$ daily and he deteriorated again. Respiratory function tests showed diminished lung compliance with increased airway resistance and $O$ increased minute volume. His dose of prednisolone was increased to $10 \mathrm{mg}$ daily and once more he improved. 옥 The prednisolone was reduced gradually and stopped after one month. At this time chest $x$-ray was normal. o He was discharged but was readmitted 3 weeks later with recurrence of his original symptoms, and again chest $\mathrm{N}$ $x$-ray showed extensive patchy shadowing, mainly $N$ perihilar. Steroids were started again, followed by further clinical and radiological improvement. They $\mathbb{\omega}$ were discontinued in September 1970. He remained $\widetilde{\sigma}$ well until May 1972, when chest $x$-ray showed an 0 increase in heart size and indistinct heart margins, due to the extensive, mainly perihilar, shadows in both lungs. Of He was given a further course of prednisolone.

Probable cryptogenic fibrosing alveolitis; normal lung biopsy. Case 9. The previous 
pregnancy of this child's mother had been complicated by the development of a chorionic carcinoma, for which she was successfully treated with methotrexate; this treatment was completed 6 months before his conception. The pregnancy was complicated by threatened abortions at 19,23 , and 26 weeks' gestation. Labour was induced and he was born at 39 weeks' gestation by breech delivery. He breathed spontaneously, weighed $3 \cdot 2 \mathrm{~kg}$, and was breast fed satisfactorily, though his weight gain was poor. He was otherwise well until 2 months of age when he developed a persistent cough with occasional vomiting. Treatment with penicillin had no beneficial effect and he was admitted to the local hospital at 4 months of age, when a provisional diagnosis of pneumonia was made. Chest $x$-ray showed a granular infiltration in both lungs. ECG was normal. Despite treatment with ampicillin, flucloxacillin, and digoxin he continued to deteriorate.

Investigations included $\mathrm{Hb} 13.1 \mathrm{~g} / 100 \mathrm{ml}$, white blood count $9000 / \mathrm{mm}^{3}$ with neutrophils $50 \%$, lymphocytes $48 \%$, and monocytes $2 \%$. Platelet count was $273,000 / \mathrm{mm}^{3}$ and ESR $37 \mathrm{~mm} / \mathrm{hr}$. Sweat sodium concentration was 21 and $19 \mathrm{mEq} / \mathrm{l}$. 24-hour urinary VMA excretion was normal at $1.0 \mathrm{mg}$. Bone marrow aspiration showed an active marrow with marked toxic changes, and some evidence of iron and possibly folate deficiency. Serum iron was $52 \mu \mathrm{g} / 100 \mathrm{ml}$, serum folate $6 \cdot 2 \mathrm{ng} / \mathrm{ml}$, and serum $B_{12} 464 \mu \mathrm{g} / \mathrm{ml}$. Serum total bilirubin was $<0.7 \mathrm{mg} / 100 \mathrm{ml}$. Serum glutamic oxoloacetic transaminase was 108 and glutamic pyruvic transaminase was $59 \mu \mathrm{mol} /$ pyruvate per $100 \mathrm{ml}$ per hr. Serum albumin was $1.9 \mathrm{~g} / 100 \mathrm{ml}$. Serum immunoglobulins were IgG $37 \mathrm{IU} / \mathrm{ml}$, IgM $308 \mathrm{IU} / \mathrm{ml}, \mathrm{IgA} 42$ $\mathrm{IU} / \mathrm{ml}$. Blood culture was sterile. Urinary amino acid concentrations were in the upper limit of normal and no abnormal urinary organic acids were detected. Lung function tests (at the time of lung biopsy) showed the total static lung compliance to be $9.4 \mathrm{ml} / \mathrm{cm} \mathrm{H}_{2} \mathrm{O}$, which is within normal limits for this age for our laboratory. Ciné swallow showed normal deglutition. Toxoplasma dye test was negative. Cytomegalovirus complement fixation titre was $<4$ and the rubella haemagglutination inhibition titre $<8$. Complement fixation tests for adenovirus, herpes simplex, influenza $\mathrm{A}, \mathrm{B}$, and $\mathrm{C}$, respiratory syncytial virus, and mycoplasma pneumonia all showed a titre of $<8$. No precipitins to Aspergillus fumigatus were present.

At 5 months of age when chest $x$-ray showed diffuse opacities, most marked in the perihilar regions, a lung biopsy was performed but the tissue appeared normal histologically. After biopsy his condition fluctuated but he remained very ill. He deteriorated further 3 weeks after biopsy with recurrence of pyrexia and crepitations at the lung bases, and was treated with a further course of ampicillin and cloxacillin and was started on prednisolone $40 \mathrm{mg}$ daily. Chest $x$-ray showed extensive confluent shadowing in both lungs. From this time he made steady improvement, which was maintained when the antibiotics were stopped. This improvement was confirmed radiologically and the dose of prednisolone was gradually reduced to $5 \mathrm{mg}$ daily over a 6 -week period. After one week at this dose his cough returned, he began to vomit and lost weight. The respiratory rate increased and crepitations were heard at the right lung base. The dose of prednisolone was increased to $15 \mathrm{mg}$ daily with subsequent clinical improvement.

Pulmonary haemosiderosis. Case 24. The latter months of pregnancy of this child's mother were complicated by ulcerative colitis. She was born after a normal delivery at 37 weeks' gestation and weighed 2.85 kg. Her condition at birth was satisfactory, but she subsequently lost weight and had to be fed by nasogastric tube. The neonatal period was also complicated by several convulsions of unknown aetiology. At the age of 6 weeks she was admitted to a local hospital with failure to thrive, respiratory difficulty, and hepatomegaly. At this time she was extensively investigated. A chest $x$-ray showed diffuse lung disease with bilateral mottling, mainly perihilar. She continued to deteriorate in spite of treatment with antibiotics, diuretics, and prednisolone, and was admitted to this hospital for further investigation in November 1971, at the age of 14 weeks.

On examination she was a pale, thin, cyanosed baby with pulse rate $180 / \mathrm{min}$ and respiratory rate $130 / \mathrm{min}$. Heart sounds were normal with no murmurs. There was poor air entry in all lung areas but no adventitial sounds. The abdomen was distended and the liver edge was palpable $10 \mathrm{~cm}$ below the rib cage and was firm in consistency. The spleen edge was palpable $2 \mathrm{~cm}$ below the rib cage. There was generalized hypotonia.

Investigations here and at the referring hospital included $\mathrm{Hb} 10.5 \mathrm{~g} / 100 \mathrm{ml}$ and white blood count $13,000 / \mathrm{mm}^{3}$ of which $71 \%$ were neutrophils, $27 \%$ lymphocytes, and $2 \%$ monocytes. Serum immunoglobulins were IgG and IgA normal, IgM $87 \mathrm{IU} / \mathrm{ml}$ (high normal). Arterial blood gases were $\mathrm{Po}_{2} 37 \mathrm{mmHg}$ and $\mathrm{PCO}_{2} 43 \mathrm{mmHg}$. Chest $x$-ray showed poor aeration of both lungs with a bilateral air bronchogram. Heart size was normal. Respiratory function tests performed at lung biopsy gave a low total static compliance of only 3 $\mathrm{ml} / \mathrm{cm} \mathrm{H}_{2} \mathrm{O}$. ECG was within normal limits. Plasma acid phosphatase was $4 \cdot 1 \mathrm{KA}$ units. Sweat electrolytes, bone marrow examination, and an intravenous pyelogram were normal. Serological tests for syphilis were negative, a skeletal survey was negative, and liver biopsy normal.

Progress. Oxygen therapy resulted in temporary improvement. A lung biopsy from the lingula showed diffuse thickening of alveolar walls with some histiocytic infiltration and an increase of reticulin, collagen, and elastic fibrils. Brownish macrophages were present in alveoli which stained positively for iron with Perls's prussian blue method for haemosiderin. Haemosiderin was also present in the alveolar walls in larger amounts in the interlobular septa (Fig. 4).

With the diagnosis of possible idiopathic pulmonary haemosiderosis in mind, a trial of a diet free of milk protein was started, but she continued to deteriorate and died 4 days after the lung biopsy. Necropsy examination revealed infradiaphragmatic total anomalous pulmonary venous drainage into the porta hepatis. 


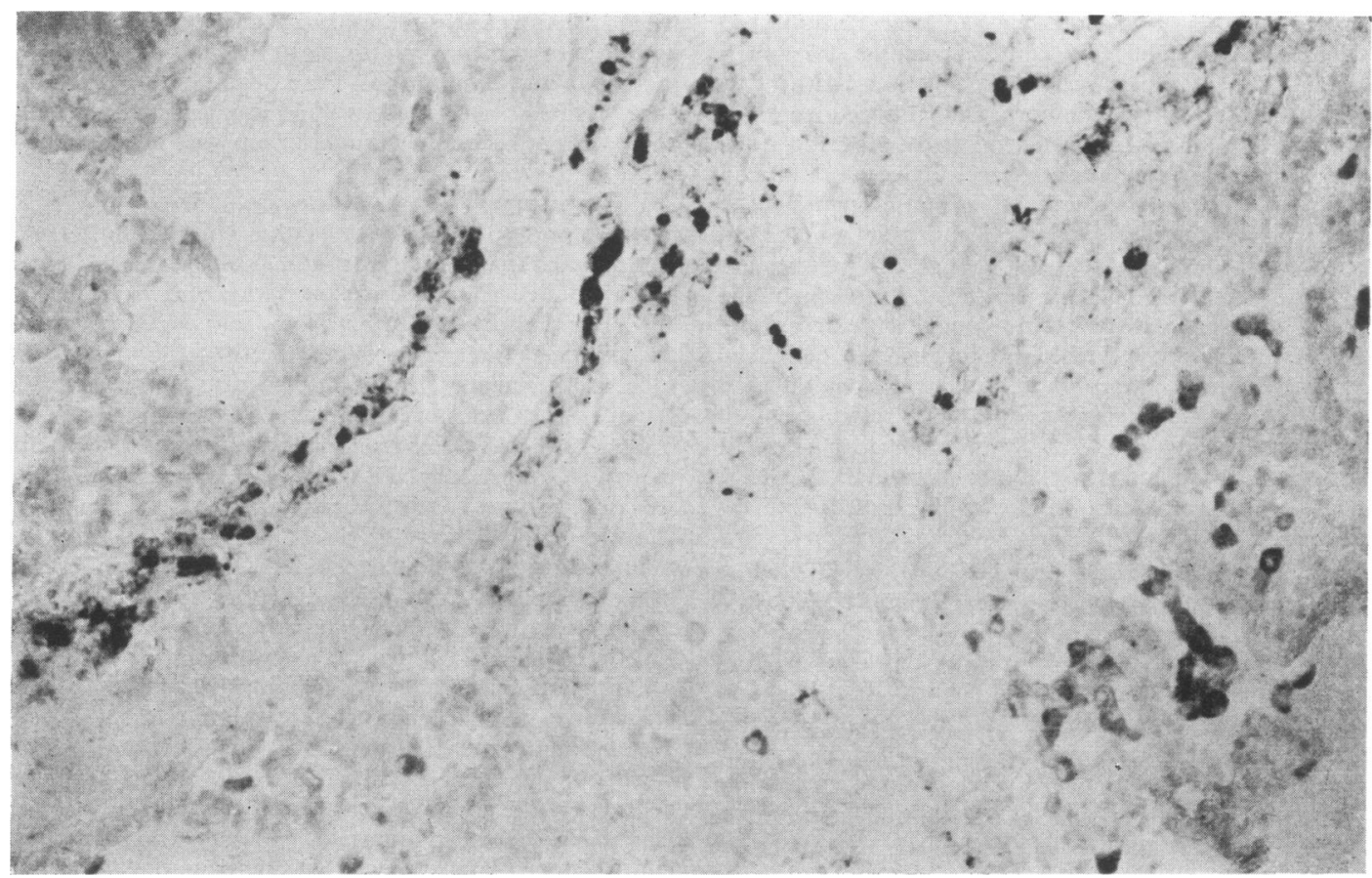

FIG. 4.-Case 24. Pulmonary haemosiderosis. The alveolar walls are thickened and iron is present in macrophages within the alveoli and in interlobular septa. (Perls's. $\times 200$.)

\section{Discussion}

Except in the most critically ill child, open lung biopsy appears to be a safe procedure. All the biopsies were helpful, even though they were not all diagnostic. Obtaining a normal biopsy in a patient with pneumocystis pneumonia, for example, would be unlikely, and therefore biopsy was felt to exclude this possibility. In Case 22, who was known to have a ventricular septal defect, persistent ductus arteriosus, and persistent foramen ovale, these lesions were felt to be insufficient to account for the diffuse lung disease which he had; but the biopsy suggested that in fact the cardiac problem was responsible, and reinvestigation confirmed the presence of a large left-to-right shunt. The lung disorder improved considerably when the persistent ductus arteriosus was ligated and the pulmonary artery banded.

The diagnostic yield is similar to that published in the series of lung biopsies in adults with diffuse lung disease reported by Scadding in 1970, where 66 open lung biopsies were carried out and 53 proved diagnostic, 8 were of doubtful categorization, and 5 were noncontributory.

The histological findings of our patients and of the three series previously reported in children are set out in Table II.

As can be seen from Table II, the causes of diffuse lung disease in children are legion. They include primary lung conditions such as cryptogenic fibrosing alveolitis, idiopathic pulmonary haemosiderosis, alveolar proteinosis, and it is not possible to make any of these diagnoses with certainty without resort to a lung biopsy. The two former are sometimes responsive to treatment with glucocorticoids, and in treatment of alveolar proteinosis steroids are said to be contraindicated (Larson and Gordinier, 1965). Sosman et al. (1957) have said that alveolar microlithiasis, another condition causing diffuse lung disease, can be diagnosed on the basis of chest $x$-ray appearances only. Classically, the features are of fine-grained pulmonary infiltrations involving the lung diffusely, with some sparing of the extreme apices and $Q$ bases. There is no known treatment for this condition.

Congenital lung infections, such as those caused by rubella, cytomegalovirus, and syphilis, may cause diffuse lung disease, but these diseases are often associated with other congenital abnormalities, and 
TABLE II

Comparison of the diagnoses found in 3 previously reported series compared with present series

\begin{tabular}{|c|c|c|c|c|}
\hline & Present series & Stringer et al. (1968) & Weng et al. (1968) & Toyama et al. (1971) \\
\hline $\begin{array}{l}\text { Cryptogenic fibrosing alveolitis } \\
\text { Pulmonary haemosiderosis } \\
P . \text { carinii } \\
\text { Aspergillosis } \\
\text { Blastomycosis } \\
\text { Farmer's lung } \\
\text { Methotrexate lung } \\
\text { Pneumonitis/bronchiolitis } \\
\text { Lipoid pneumonia } \\
\text { Visceral larva migrans } \\
\text { Choriocarcinoma } \\
\text { Noncaseating granuloma } \\
\text { Carcinoma of thyroid } \\
\text { Hystiocytosis X } \\
\text { Giant cell pneumonia } \\
\text { Wilson-Mikity } \\
\text { Emphysema } \\
\text { No diagnosis }\end{array}$ & $\begin{array}{l}8 \\
2 \\
5\end{array}$ & $\begin{array}{l}1 \\
1 \\
1 \\
1\end{array}$ & $\begin{array}{l} \\
1 \\
1 \\
1 \\
3\end{array}$ & $\begin{array}{l}3 \\
1 \\
1 \\
2 \\
1 \\
2 \\
1\end{array}$ \\
\hline Total & 24 & 16 & 16 & 11 \\
\hline
\end{tabular}

can usually be excluded on the basis of appropriate virological and serological studies.

Neoplastic infiltrations in acute leukaemia and histiocytosis-X may cause diffuse lung disease. Weng et al. (1968) made a diagnosis of histiocytosis by lung biopsy. However, this diagnosis can usually be made by other investigations, such as skeletal survey and skin or lymph node biopsy, and lung biopsy is usually unnecessary. Stringer et al. (1968) reported carcinoma of the thyroid gland and chorion carcinoma as causing diffuse lung disease, both being diagnosed by lung biopsy.

Conditions such as cystic fibrosis of the pancreas and H-type tracheo-oesophageal fistula may cause diffuse lung disease, but the history from these patients is often diagnostic.

Pulmonary oedema secondary to pulmonary venous obstruction, such as in total anomalous pulmonary venous drainage, may present with a picture suggestive of primary lung disease, as did Case 24. In this condition cardiomegaly may be absent, though the ECG is usually abnormal with evidence of right atrial and right ventricular hypertrophy and RS reversal. In none of the other series did congenital heart disease masquerade as a primary lung problem.

Other infections, such as miliary tuberculosis and giant cell pneumonias associated with the common exanthema, are also usually diagnosed on the basis of the history and other investigations, without resort to lung biopsy. Pulmonary fungal infections are usually confirmed on the basis of the appropriate sputum cultures, serological and skin tests, and lung biopsy is seldom needed. Only one case of blastomycosis and two cases of aspergillosis in children have been diagnosed at lung biopsy and published in America.

Cryptogenic fibrosing alveolitis describes a clinical and histological picture whicb may well, in the light of further knowledge, include a variety of disorders. In this series 10 patients were thought to have the clinical features of cryptogenic fibrosing alveolitis but this was only confirmed in 8 by biopsy (to be reported).

We are grateful to the physicians of The Hospital for Sick Children, Great Ormond Street, London, for permission to report details of patients under their care.

\section{REFERENCES}

Larson, R. K., and Gordinier, R. (1965). Pulmonary alveolar proteinosis. Annals of Internal Medicine, 62, 292.

Scadding, J. G. (1970). Lung biopsy in the diagnosis of diffuse lung disease. British Medical fournal, 2, 557.

Scadding, J. G., and Hinson, K. F. W. (1967). Diffuse fibrosing alveolitis. Thorax, 22, 291.

Sosman, M. C., Dodd, G. D., Jones, W. D., and Pillmore, G. U. (1957). The familial occurrence of pulmonary alveolar microlithiasis. American fournal of Roentgenology, 77, 947.

Stringer, R. J., Stiles, Q. R., Lindesmith, G. G., Meyer, B. W., and Jones, J. C. (1968). Use of lung biopsy in diagnosis of pulmonary lesions in children. American Surgeon, 34, 810.

Toyama, W. M., Reyes, C. N., Lawton, B. R., and Sautter, R. D. (1971). Open lung biopsy in infants and children. Archives of Surgery, 103, 195.

Weng, T-R., Levison, H., Wentworth, P., Simpson, J., and Moes, C. A. F. (1968). Open lung biopsy in children. American Review of Respiratory Diseases, 97, 673.

Correspondence to Professor D. Hull, Department of Child Health, City Hospital, Hucknall Road, Nottingham NG5 1PB. 